\title{
Patients' Attitudes, Awareness, and Opinions About Community Pharmacies in Japan: Next Steps for the Health Support Pharmacy System
}

This article was published in the following Dove Press journal: Integrated Pharmacy Research and Practice

\author{
Noritake Hirota $\mathbb{1}^{1,2}$ \\ Noboru Okamura' \\ 'Department of Clinical Pharmacy, \\ School of Pharmaceutical Sciences, \\ Mukogawa Women's University, \\ Nishinomiya, Japan; ${ }^{2}$ General \\ Incorporated Association Osaka \\ Pharmaplan, Aozora Pharmacy, Osaka, \\ Japan
}

Purpose: Despite the formal establishment of the Health Support Pharmacy system, few community pharmacies have transitioned to this new designation in Japan. Moreover, patients' perspectives on the usefulness of health-support pharmacies and community pharmacies have not yet been investigated. In this work, we investigated patients' attitudes, opinions, and awareness as users of member pharmacies of the Japan Federation of Democratic Medical Institutions (Min-Iren), with respect to two essential functions provided by community pharmacies - primary care and health support — to identify modern challenges facing community pharmacies.

Methods: Regular visitors to participating Min-Iren community pharmacies were asked to complete an anonymous questionnaire. Responses were compared between users of healthsupport pharmacies and other pharmacy types, as well as between members and nonmembers of "collaborating organizations" (CO). CO is organizational partners of Min-Iren whose activities support affiliated facilities. Logistic regression analysis was performed to explore the predictive value of different factors on pharmacies' primary-care and healthsupport functionality.

Results: A total of 181 Min-Iren community pharmacies (51.7\%: 181/350) participated in this study, and most patients answered the questionnaire $(97.7 \%, \mathrm{n}=2623)$. Relatively few patients recognized the term "Health Support Pharmacy" (12.2\%). CO members tended to have a superior understanding of a wide variety of services provided by CPs as compared to non-members. Statistically significant predictors of primary-care and health-support functionality included male gender, having a primary-care pharmacist, age $\geq 60$ years, recognition of the term "Health Support Pharmacy" and CO membership.

Conclusion: CO members, a class of patients with a superior awareness of health promotion, demonstrated a good understanding of the variety of services provided by community pharmacies and tended to positively rate their pharmacy. Moving forward, efforts to raise awareness about the importance of health-promotional activities among community pharmacy users should further reinforce the primary-care and health-support functions of community pharmacies.

Keywords: community pharmacy, health-support pharmacy, primary-care function, healthsupport function, patient awareness

\section{Introduction}

Medical advances continue to place additional demands on the service provided by local pharmacies. Thus, reducing this burden is a task of global relevance. Community pharmacies and community pharmacists are required to provide a diverse range of
Correspondence: Noritake Hirota Pharmaplan, Aozora Pharmacy, 3-6-8 Nozato, Nishiyodogawa-Ku, Osaka City Osaka 555-0024, Japan

Tel $+8 \mathrm{I}-6-6477-8088$

Fax $+8 \mathrm{I}-6477-8090$

Email n-hirota@faruma.co.jp
Integrated Pharmacy Research and Practice 2020:9 243-256 
functions, such as influenza vaccination, ${ }^{1,2}$ weight management for local residents, ${ }^{3,4}$ smoking cessation support, ${ }^{4,5}$ emergency contraceptive provision, ${ }^{6}$ HIV testing, ${ }^{7}$ simple biochemical testing (eg HbAlc levels), ${ }^{8}$ mental health promotion, ${ }^{9}$ lifestyle interventions, ${ }^{10}$ health consultation activities, ${ }^{11,12}$ holding informational seminars to improve health literacy among patients and local residents, ${ }^{13}$ ensuring the correct use of opioid painkillers in palliative care, ${ }^{14}$ and community pharmacist-led follow-up to reduce cardiovascular event risk. ${ }^{15}$ Community pharmacies have been increasingly emphasized in public health initiatives in the UK, ${ }^{16}$ while in Canada, one study showed that patient utilization of community pharmacies can effectively reduce their need to access emergency care. ${ }^{17}$ These trends signify that community pharmacies hold potential beyond their conventional roles (compounding and dispensing drugs), as a locus of social capital and public goods.

Currently, there are about 60,000 community pharmacies in Japan, which are expected to serve their communities as health information hubs. ${ }^{18}$ Japan is approaching a major inflection point in its population structure. By 2025, the post-war generation, ie people born after World
War II (around 1950), will start to reach the age of 75 (often defined as the start of "late-old age") in greater numbers. This generation constitutes a major proportion of Japan's population structure. The Cabinet Office has estimated that by 2025 , elderly adults aged $\geq 65$ years will exceed $30 \%$ of the country's population, and $18 \%$ of them are expected to be "late-elderly" $\geq 75$ years. ${ }^{19}$ In anticipation of these changes, the Ministry of Health, Labor and Welfare (MHLW) is advocating for the construction of a community-based integrated care system, to provide elderly adults with uninterrupted access to medical and long-term care services-24 hours a day, 365 days a year - in the comfort of their neighborhoods and communities in which they have settled. The MHLW continues to work on implementing this framework-known as the Integrated Community Care System ${ }^{20}$-throughout the country, with a target completion date of 2025. The roles expected of community pharmacies in the uninterrupted provision of medical and long-term care services under the Integrated Community Care System correspond to those articulated in the Pharmacy Vision for Patients, proposed by the MHLW in October 2015 (Figure 1). ${ }^{21}$ One concrete

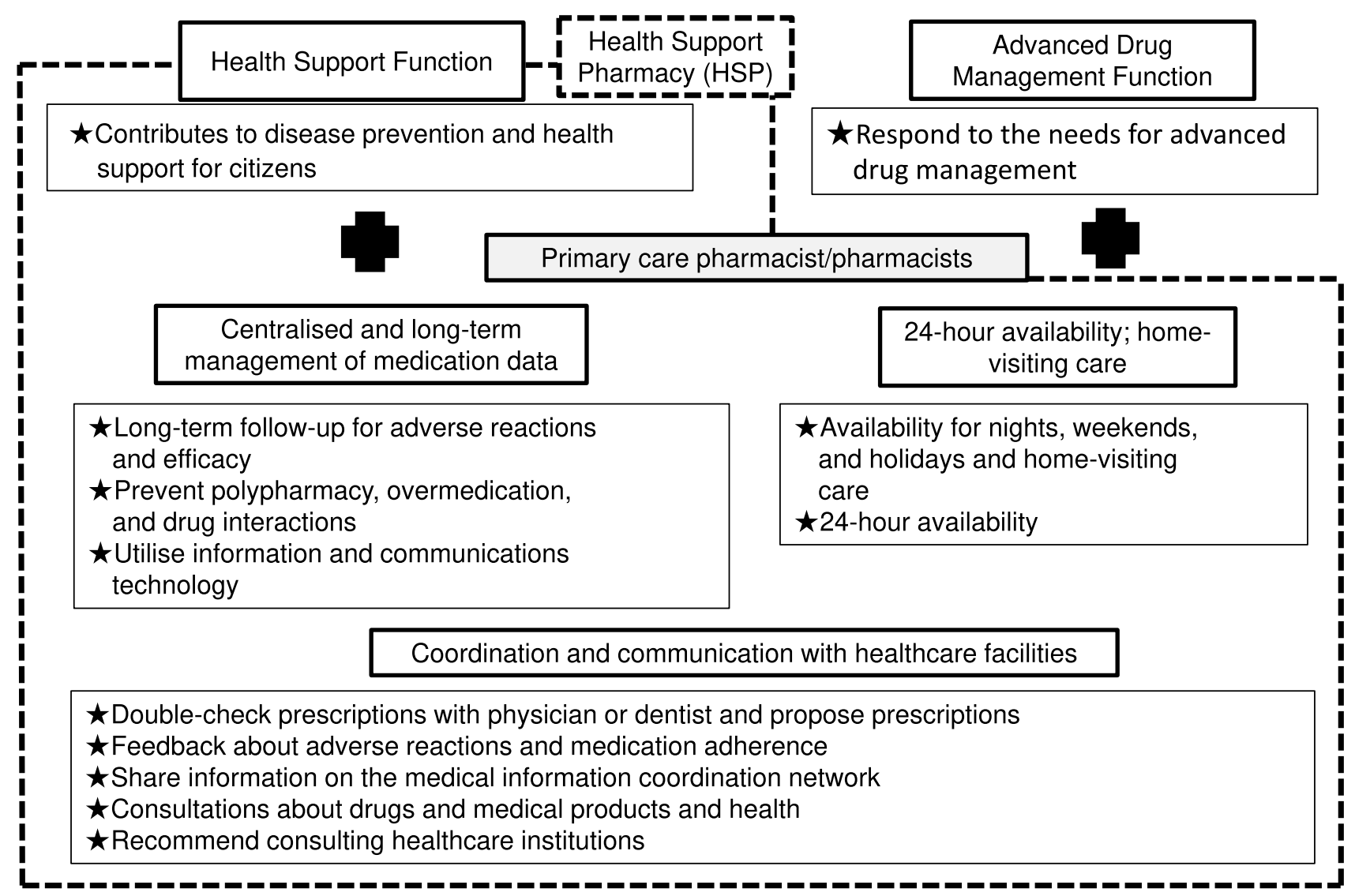

Figure I Pharmacy vision for patients. 
realization of this policy is the establishment of a new "Health Support Pharmacy" system in April 2014, pharmacies started to be certified and registered under the system in October 2014.

The background to the establishment of Health Support Pharmacy was the criticism from the public and patients for the activities of regional pharmacies in Japan. In recent years, the operations of many regional pharmacies have become more focused on prescription dispensing, and the role that the original pharmacy should play has tended to be neglected. To solve these problems, the MHLW led to the creation of the Health Support Pharmacy system. The Japan Pharmaceutical Association is backing up this policy.

The definition of Health Support Pharmacy includes two key functions: primary-care function, including the centralized management of prescriptions, 24-hour availability, home services, and coordination with medical and longterm care facilities, and health-support function, including disease prevention, pre-illness intervention, and healthpromotion activities targeting the general public. By the official 2025 start of the Integrated Community Care System era, the MHLW is aiming to have certified a minimum of one pharmacy in every junior-high-school district in the country, totaling to approximately 15,000 Health Support Pharmacies. However, as of late 2019, that number was only 1797 , just $~ 3 \%$ of all pharmacies in Japan.

Research on the utilization pattern of Health Support Pharmacies is limited. Hirota and colleagues showed that continued participation in a variety of Health Support Pharmacy-run informational seminars can significantly change attendees' attitudes and behaviors towards drugs and health. ${ }^{13}$ Sato and colleagues revealed that proper resources and expertise are critical factors that influence the quality of Health Support Pharmacy services. ${ }^{22}$ The push towards the Health Support Pharmacy framework must be driven by community pharmacies. Yet despite this obligation, the process of registering community pharmacies under the new system is not going according to the plans. One reason for the lack of Health Support Pharmacy registrations, discovered by the authors in a previous work, was the high number of physical obstacles in meeting the registration criteria (number of health-support pharmacists, OTC placement, etc.). ${ }^{23}$ However, the needs and opinions of the patients who utilize Health Support Pharmacies have yet to be investigated in a large-scale cross-sectional survey.
In this work, we investigated patients' attitudes, opinions, and awareness about the two crucial functions fulfilled by community pharmacies - primary care and health support - at member pharmacies of the Japan Federation of Democratic Medical Institutions (Min-Iren).

Similar to a pharmacy, any healthcare center that issues prescriptions - a chief demand of Min-Iren pharmaciescan join the organization. Other kinds of groups whose activities support healthcare and management at such centers, such as medical co-operatives and "Friends of Health" groups, can also join: in Min-Iren, they are referred to as "collaborating organizations". ${ }^{24}$

Our hypothesis was twofold. First, we suspected that patients who utilize Health Support Pharmacies would have a greater need for pharmacy services and have a better knowledge of drugs and general health in various dimensions than patients who visit non-Health Support Pharmacy pharmacies. Second, we hypothesized that similar differences may be present between patients who are members of MinIren "collaborating organizations" compared with nonmembers. By exploring patients' awareness of these centers' primary-care and health-support functions, we hope to shed light on the most important tasks - from a patient perspective - still to be addressed by Japanese community pharmacies.

Patients who use community pharmacies have a wide variety of illnesses. In this study, we did not deliberately investigate the difference in patient consciousness due to illness. The reason is that the focus was on investigating the level of consciousness as a whole.

\section{Methods}

\section{Subjects}

This study targeted member pharmacies of the Japan Federation of Democratic Medical Institutions (Min-Iren). As of June 2019, there were 350 such facilities in Japan (below, "Min-Iren pharmacies")

\section{Survey Period, Eligibility, and Method Subjects \\ Survey Period}

The patient questionnaires were sent to the participating Min-Iren pharmacies in June 2019, accompanied by consent forms explaining the purpose of the research and a reply envelope. Pharmacy staff returned the completed forms to the research team in the provided envelope, once the designated number of questionnaires had been administered (see 2-2). The survey was conducted from July to October 2019. 


\section{Survey Eligibility and Sample Sizes}

Eligibility was limited to adult patients who routinely visited the pharmacy in question; first-time users were excluded. The number of questionnaires to be administered was determined independently by each pharmacy, based on a target sample size, communicated by the research team, of about $1 \%$ of its average monthly users.

\section{Survey Method}

During the survey period, pharmacy staff solicited the first 1-2 patients of the day (ie immediately after opening the pharmacy) to complete the questionnaire. Provided the circumstances permitted, the staff continued this protocol each day until the designated sample size was reached.

Pharmacy staff first gave each patient the aforementioned consent form detailing the purpose of the research, accompanied by a verbal explanation of its contents. Only consenting patients were administered the survey. Pharmacy staff did not assist patients or intervene in any way as they completed the questionnaire form. The survey was conducted anonymously.

\section{Survey Items}

The survey items (questions) in the questionnaire form are presented in Figure 2. The survey items were originally created to explore the patient's awareness of the "family function" and "health-support function" provided by the regional pharmacies, referring to the "Survey on family pharmacists and pharmacies" 25 conducted by the MHLW did.

\section{Data Aggregation and Statistical Testing} a) Data Aggregation

Questionnaire responses were entered into spreadsheet software (Microsoft Excel 2019). For each item, the number of patients who selected each response was counted.

\section{b) Statistical Testing}

\section{b-I) Chi-Square Test for Independence}

Chi-square tests were performed to check for differences in the distribution of responses based on pharmacy and user type. Users of a designated Health Support Pharmacy were compared with non-Health Support Pharmacy users, while "collaborating organizations" members were compared with unaffiliated patients. Each status's predictive value for certain response(s) was calculated in terms of odds ratio for each question.

\section{b-2) Logistic Regression Analysis}

Logistic regression analysis was performed to ascertain the predictive value of each questionnaire item on pharmacies' fulfilment of the two official functions of community pharmacies: primary care and health support. One-stop prescription filling, ie "Yes" on Q2-2 (Figure 2), was adopted as the proxy for primary-care function, considering that patients bringing all their prescriptions to a single pharmacy - rather than multiple locations - was a good indication that patients treated the pharmacy in question as primary-care function.

Interest in attending pharmacy-led informational seminars about medicine and general health, ie "Yes" on Q4-5 (Figure 2), was adopted as the proxy for health-support function. While community pharmacy services act to support users' health in a variety of ways, there is particularly strong evidence ${ }^{13}$ that participation in such seminars, in which pharmacies provide health-related information to patients or local residents, improves attendees' health literacy. ${ }^{26}$

Separate logistic regressions were conducted to determine the predictive value of each of the remaining questionnaire items (X: explanatory variables) on primary care and health support (Y: response variables). Response data were binarized as "1" or " 0 ", denoting the question's most positive response(s), and all other responses, respectively. There were some exceptions: age (1: $<60$ years, $0: \geq 60$ years), gender (1: male, 0 : female), and occupational status (1: company employee or self-employed ("employed"), 0 : other). Odds ratios (OR), 95\% confidence intervals (CI), and probability (p) values were calculated for all regression analyses.

\section{Statistical Processing}

Chi-square testing and logistic regression analysis were conducted using EZR ver.1.27 (Saitama Medical Center, Jichi Medical School). ${ }^{27}$ Differences of $p<0.05$ were considered statistically significant.

\section{Ethical Considerations}

This study was conducted with the approval of the ethics committees of Mukogawa Women's University (approval ID: No. 19-01) and the Japan Federation of Democratic Medical Institutions (43-004), in compliance with the Ethical Principles for Medical Research Involving Human Subjects (Declaration of Helsinki). 


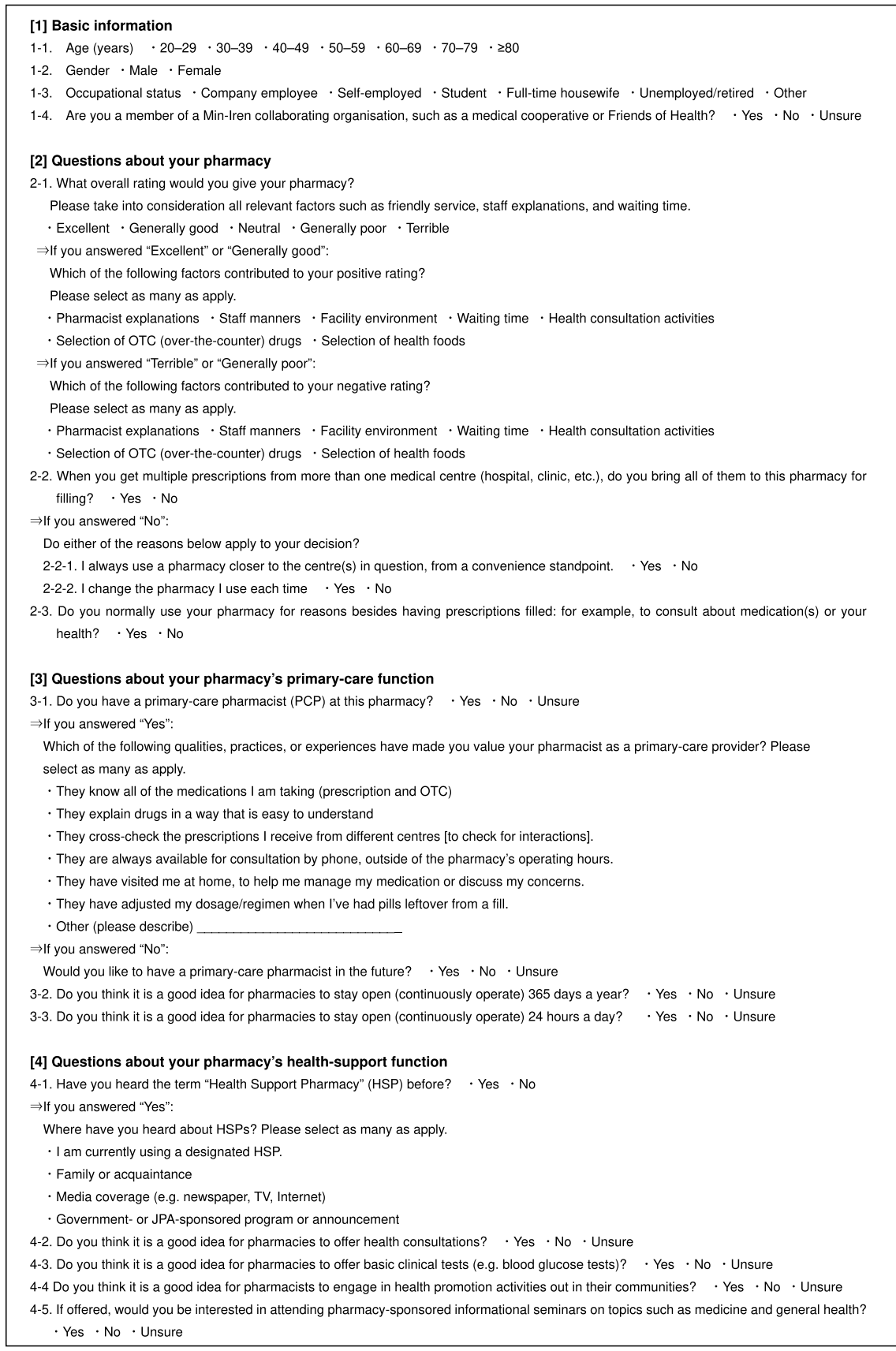

Figure 2 Patient questionnaire.

\section{Results}

\section{Response Rates}

Just over half of the Min-Iren member pharmacies, who were sent the questionnaire and consent forms, agreed to participate in the study $(51.7 \%, \mathrm{n}=181 / 350)$. In total, study summary and consent forms were given to well over two thousand patients across all pharmacies, the vast majority of whom consented to participate in the survey and completed the questionnaire $(97.7 \%, \mathrm{n}=2623 / 2685)$. On average, 14.5 patients per pharmacy completed the questionnaire (range: 1-95). Just under half of the questionnaires were returned from registered Health Support Pharmacies $(43.2 \%, \mathrm{n}=$ 1133), while about half of respondents affirmed "collaborating organizations" membership (50.3\%).

\section{Pharmacy Attributes}

This section provides the breakdown of all participating pharmacies by reimbursement category. Reimbursement 
was calculated according to basic dispensing fee 127 for nearly three-quarters of the pharmacies $(74.0 \%, \mathrm{n}=134$; "type 1 pharmacies" below), and other fee categories for the remainder $(26.0 \%, \mathrm{n}=47)$. Just under a third of the pharmacies were registered Health Support Pharmacies $(30.4 \%, 55)$, of which the majority were type $1(60.0 \%$, $\mathrm{n}=33$; other categories: $\mathrm{n}=22$ ). Just under two thirds of the pharmacies had registered for the additional community support system ${ }^{28}(65.2 \%, \mathrm{n}=118)$, an extra premium offered to pharmacies that fulfilled primary-care functions: eg 24-hour availability for phone consultations, dispensing of narcotic drugs, house calls, and assigning a Logistic regression analysis was performed to ascertain the predictive value of each questionnaire item on pharmacies' fulfilment of the two official functions of community pharmacies: primary care and health support. One-stop prescription filling, ie "Yes" on Q2-2 (Figure 2), was adopted as the proxy for primary-care function, considering that patients bringing all their prescriptions to a single pharmacy-rather than multiple locations - was a good indication that patients treated the pharmacy in question as a primary-care pharmacist to patients. This premium was intended for type 1 pharmacies in principle: of facilities that had not registered for it, about one quarter were type 1 pharmacies $(27.0 \%, \mathrm{n}=17$; other categories: $73.0 \%, \mathrm{n}=46$ ).

Since this addition was originally introduced to encourage Health Support Pharmacies to fulfil primary-care roles, we estimate that primary-care functionality was realized (in practice) by just over three-quarters of the participating pharmacies $(77.3 \%, \mathrm{n}=140)$ : the 22 nontype-1 pharmacies registered as Health Support Pharmacies, plus the 118 pharmacies which had registered for the community support system premium. Moreover, while only 55 pharmacies had officially registered as Health Support Pharmacies, 52 claimed they intended to register as one, and another 47 stated that registration was under discussion. Thus, we estimate that most of the participating pharmacies were fulfilling the healthsupport functionality desired of Health Support Pharmacies through their activities, to at least some extent $(85.1 \%, \mathrm{n}=154)$.

\section{Basic Information of the Respondents} a) Age

Older adults comprised the majority of the respondents (age $\geq 60$ years: $71.4 \%,<59$ years: $28.0 \%$ ). There were no significant differences in the age-population structure between Health Support Pharmacies and non-Health Support Pharmacies or between "collaborating organizations" members and non-members (Table 1).

\section{b) Gender}

Most of the respondents were females $(55.9 \%, \mathrm{n}=1466$ vs male: $43.5 \%, \mathrm{n}=1142$; no response: $0.6 \%, \mathrm{n}=15$ ). There were no significant differences in gender ratio between Health Support Pharmacies and non-Health Support Pharmacies or between "collaborating organizations" members and non-members.

\section{c) Occupational Status}

Majority of the respondents were unemployed/retired $(36.2 \%, \mathrm{n}=950)$. The next most common occupational status was company employee $(21.8 \%, \mathrm{n}=571)$, followed in descending order by: full-time housewife $(18.6 \%, \mathrm{n}=488)$, selfemployed $(17.3 \%, \mathrm{n}=192)$, other $(14.3 \%, \mathrm{n}=374)$, no response $(1.3 \%, \mathrm{n}=35)$, and student $(0.5 \%, \mathrm{n}=13)$. There were no significant differences in the distribution of occupation status between Health Support Pharmacy users and

Table I Age Distribution of the Respondents

\begin{tabular}{|l|l|l|l|l|l|}
\hline \multicolumn{2}{|c|}{} & \multicolumn{2}{l|}{ Health Support Pharmacy User } & \multicolumn{2}{l|}{ Collaborating Organization Member } \\
\hline Age (Years) & Total & Yes & No & Yes & No \\
\hline $20-29$ & $47(1.8 \%)$ & $30(2.6 \%)$ & $17(1.1 \%)$ & $14(1.1 \%)$ & $33(2.5 \%)$ \\
$30-39$ & $114(4.3 \%)$ & $53(4.7 \%)$ & $61(4.1 \%)$ & $33(2.5 \%)$ & $81(6.2 \%)$ \\
$40-49$ & $260(9.9 \%)$ & $134(11.8 \%)$ & $126(8.5 \%)$ & $93(7.1 \%)$ & $167(12.8 \%)$ \\
$50-59$ & $315(12.0 \%)$ & $130(11.5 \%)$ & $185(12.4 \%)$ & $137(10.4 \%)$ & $178(13.7 \%)$ \\
$60-69$ & $602(23.0 \%)$ & $246(21.7 \%)$ & $356(23.9 \%)$ & $297(22.5 \%)$ & $305(23.4 \%)$ \\
$70-79$ & $873(33.3 \%)$ & $362(32.0 \%)$ & $511(34.3 \%)$ & $499(37.8 \%)$ & $374(28.7 \%)$ \\
$\geq 80$ & $395(15.1 \%)$ & $168(14.8 \%)$ & $227(15.2 \%)$ & $237(18.0 \%)$ & $158(12.1 \%)$ \\
No response & $17(0.6 \%)$ & $10(0.9 \%)$ & $7(0.5 \%)$ & $9(0.7 \%)$ & $8(0.6 \%)$ \\
Total & $2623(100.0 \%)$ & $1133(100.0 \%)$ & $1490(100.0 \%)$ & $1319(100.0 \%)$ & $1304(100.0 \%)$ \\
\hline
\end{tabular}


non-users or between "collaborating organizations" members and non-members.

\section{Overall Ratings of Pharmacy Service}

Respondents' overall ratings of their pharmacy-encompassing factors such as friendly service, pharmacist explanations, and waiting time-were categorized as follows: Excellent: $46.6 \%(\mathrm{n}=1223)$, Generally good: $41.3 \%(\mathrm{n}=$ 1084), Neutral: $9.5 \%(\mathrm{n}=249)$, Generally poor: $1.5 \%(\mathrm{n}=$ 39), Terrible: $0.3 \%(\mathrm{n}=8)$, No response: $0.8 \%(\mathrm{n}=20)$.

Health Support Pharmacy users were no less likely to give an "Excellent" rating (versus all other responses) than non-users (OR: 0.865, p =0.069); however, "collaborating organizations" members were more than twice as likely to rate their pharmacy's service as "Excellent" (OR:2.261, $\mathrm{p}<0.0001$ ) as non-members.

\section{Reasons for Positive and Negative Appraisal of Pharmacy Service}

The reason most frequently affirmed by patients who rated their pharmacy's service as "excellent" or "generally good" overall was the quality of pharmacists' explanations $(\mathrm{n}=1914)$, followed in descending order by: staff manners $(\mathrm{n}=1464)$, facility environment $(\mathrm{n}=750)$, waiting time $(\mathrm{n}=546)$, health consultation activities $(\mathrm{n}=196)$, selection of OTC drugs $(\mathrm{n}=81)$, and selection of health foods $(n=56)$.

The reason most frequently affirmed by patients who rated their pharmacy's service as "terrible" or "generally poor" overall-by an overwhelming margin — was waiting time $(\mathrm{n}=44)$. Other, minor complaints included staff manners $(n=2)$, facility environment $(n=1)$, and health consultation activities $(\mathrm{n}=1)$.

\section{One-Stop Prescription Filling}

Respondents tended to not bring all prescriptions obtained from multiple providers to be filled at the pharmacy in question: Yes: 41.8\%, $\mathrm{n}=1097$; No: $54.0 \%, \mathrm{n}=1417$, No response: $4.2 \%, \mathrm{n}=109$. As noted above, responding "Yes" to this question was interpreted as a proxy for patients' perceptions of their pharmacy as a provider of primary care.

Health Support Pharmacy users were equally likely to affirm filling all prescriptions at the pharmacy in question than non-users ("Yes" vs all other responses, OR: 0.980, $\mathrm{p}=0.776$ ), while "collaborating organizations" members were significantly more likely to do so than non-members (OR:1.78, $\mathrm{p}<0.0001)$.

\section{Reasons Given for Not Filling All Prescriptions at a Single Location} a) Convenience

Convenience, ie preferring to use pharmacy (or pharmacies) closer to the center(s) they visit regularly, was the major factor noted by most of the patients who were not filling all prescriptions at the pharmacy in question (Yes: $82.5 \%, \mathrm{n}=1167$; No: $5.2 \%, \mathrm{n}=74$; No response: $12.3 \%$, $\mathrm{n}=174)$.

This reason was equally likely to be affirmed (vs all other responses) by Health Support Pharmacy users as non-users (OR: $0.825, p=0.186$ ), and by "collaborating organizations" members as non-members (OR:0.888, $\mathrm{p}=0.400$ ).

\section{b) Choosing a Different Pharmacy for Each Visit}

Selection of a different pharmacy for each visit was cited by relatively fewer patients who were not filling all their prescriptions at the pharmacy in question (Yes: $3.2 \%, \mathrm{n}=$ 45; No: 30.5\%, $\mathrm{n}=432$; No response: $66.3 \%, \mathrm{n}=938$ ).

This reason was equally likely to be affirmed (vs all other responses) by Health Support Pharmacy users as non-users (OR: 1.386, $\mathrm{p}=0.288$ ), and by "collaborating organizations" members as non-members (OR:0.609, $\mathrm{p}=0.129$ ).

\section{Pharmacy Usage for Reasons Besides Filling Prescriptions}

Respondents tended to deny typically visiting their pharmacy for reasons besides prescription filling, such as consultations about medications or general health (Yes: $14.3 \%, \mathrm{n}=374$; No: $82.0 \%, \mathrm{n}=2150$; No response: $3.8 \%, \mathrm{n}=99)$.

Health Support Pharmacy users were equally likely to affirm usage of other services as non-users ("Yes" vs all other responses, OR: 0.908, $\mathrm{p}=0.399$ ), while "collaborating organizations" members were significantly more likely to do so than non-members (OR: 1.615, $\mathrm{p}<0.0001)$.

\section{Primary-Care Pharmacist Assignment}

The majority of respondents denied having a primary-care pharmacist (Yes: 12.4\%, $\mathrm{n}=326$; No: $\mathrm{n}=72.5 \%, 1901$; Unsure: $12.9 \%, \mathrm{n}=338$; No response: $2.2 \%, \mathrm{n}=58$ ).

Health Support Pharmacy users were equally likely to affirm having a primary-care pharmacist as non-users ("Yes" vs all other responses, OR: 0.859, p = 0.231), while "collaborating organizations" members were 
significantly more likely to do so than non-members (OR:1.664, $\mathrm{p}<0.0001$ ).

\section{Experiences Leading Patients to Regard Pharmacists as Primary-Care Pharmacists}

The experience most frequently cited by patients who affirmed having a primary-care pharmacist that made them appreciate their value was realizing that $\mathrm{s} / \mathrm{he}$ knew all of their current (prescription and OTC) medications $(\mathrm{n}=226)$, followed in descending order by: easy-to-understand drug explanations ( $\mathrm{n}$ $=219$ ), cross-checking prescriptions from different centers [to check for interactions] ( $\mathrm{n}=95)$, and adjusting dosage/regimens in the event of leftover pills $(\mathrm{n}=59)$.

\section{Desire for a Primary-Care Pharmacist} Among Patients without One

When patients without a primary-care pharmacist were asked whether they wanted to be assigned one, their responses were quite mixed (Yes: $18.8 \%, \mathrm{n}=432$; No: $22.2 \%, \mathrm{n}=510$; Unsure: $41.5 \%, \mathrm{n}=955$; No response: $17.6 \%, \mathrm{n}=404$ ).

Health Support Pharmacy users were equally likely to report wanting their primary-care pharmacist as non-users ("Yes" vs all other responses, OR: 0.856, p = 0.170), while "collaborating organizations" members were significantly more likely to do so than non-members (OR: 1.501, p < $0.0001)$.

\section{Opinions on 365-Day and 24-Hour Pharmacy Access}

Patients' opinions about year-round access to pharmacies were split (Yes: 26.6\%, $\mathrm{n}=698$; No: $27.7 \%, \mathrm{n}=727$; Unsure: $37.1 \%, \mathrm{n}=972$; No response: $8.6 \%, \mathrm{n}=226$ ).

Health Support Pharmacy users were significantly more likely to agree with the question than non-users ("Yes" vs all other responses, OR: 1.437, $\mathrm{p}=0.0001$ ), whereas "collaborating organizations" members were significantly less likely to do so (OR:0.749, p < 0.0001).

Overall, the patients were slightly opposed to the idea about round-the-clock access to pharmacies (Yes: 17.1\%, $\mathrm{n}=448$; No: $36.9 \%, \mathrm{n}=969$; Unsure: $36.3 \%, \mathrm{n}=952$; No response: $9.7 \%, \mathrm{n}=254$ ).

Health Support Pharmacy users were somewhat more likely to agree with the question than non-users, although not reaching statistical significance ("Yes" vs all other responses, OR: $1.209, \mathrm{p}=0.079$ ); "collaborating organizations" members, on the other hand, were significantly less likely to agree (OR:0.734, $\mathrm{p}=0.0004)$.

\section{Public Awareness of Health Support Pharmacies}

The majority of the respondents did not recognize the term "Health Support Pharmacy" (Yes: 12.2\%, n = 319; No: $79.1 \%, \mathrm{n}=2075$; No response: $8.7 \%, \mathrm{n}=229$ ).

Health Support Pharmacy users were no more likely to recognize the term than non-users ("Yes" vs all other responses, OR: $1.028, \mathrm{p}=0.761$ ), whereas "collaborating organizations" members were more than twice as likely to do so (OR:2.465, $\mathrm{p}<0.0001)$.

Knowledge that their pharmacy was a registered Health Support Pharmacy was the reason most frequently given by patients who knew the term $(n=154)$. Other major sources cited included (in descending order): media coverage $(n=75)$, family members and acquaintances $(\mathrm{n}=55)$, and governmentor JPA-sponsored programs or announcements $(n=41)$.

\section{Opinions on Access to Health Consultations and Simple Health Tests at Pharmacies}

Over three-quarters of the respondents regarded being able to access health consultation services at pharmacies as a good thing (Yes: $78.7 \%, \mathrm{n}=2064$; No: $1.3 \%, \mathrm{n}=35$; Unsure: $12.2 \%, \mathrm{n}=319$; No response: $7.8 \%, \mathrm{n}=205$ ).

Health Support Pharmacy users were equally likely to agree with the statement (vs all other responses) as nonusers (OR: 1.099, $\mathrm{p}=0.449$ ), while "collaborating organizations" members were significantly more likely to agree than non-members (OR: 1.369, $\mathrm{p}=0.00684$ ).

Just under two-thirds of patients regarded access to simple tests (eg blood glucose measurement) at pharmacies as a good thing (Yes: $65.8, \mathrm{n}=1725$; No: $3.3 \%, \mathrm{n}=$ 87; Unsure: $22.5 \%, \mathrm{n}=590$; No response: $8.4 \%, \mathrm{n}=221$ ).

No significant differences in agreement ("Yes" vs all other responses) were observed between Health Support Pharmacy users and non-users (OR: 1.106, $\mathrm{p}=0.291$ ) or between "collaborating organizations" members and nonmembers (OR: 1.041, $\mathrm{p}=0.683$ ).

\section{Opinions on Pharmacist-Led Health-Promotion Activities Out in the Community}

The majority of the respondents regarded pharmacists doing health-promotional activities out in the community as a good thing (Yes: $74.4 \%, \mathrm{n}=1952$; No: $1.1 \%, \mathrm{n}=30$; Unsure: $16.2 \%, \mathrm{n}=426$; No response: $8.2 \%, \mathrm{n}=215$ ). 
Health Support Pharmacy users were equally likely to agree with the idea (vs all other responses) as non-users (OR: $1.105, p=0.371$ ), while "collaborating organizations" members were significantly more likely to agree than non-members (OR: 1.431, $\mathrm{p}=0.0005$ ).

\section{Interest in Attending Pharmacy-Led Seminars on Medicine and General Health}

Patients showed a mixed response regarding their interest in attending pharmacist-led informational seminars on medicine and general health (Yes: $30.1 \%, \mathrm{n}=790$; No: $7.8 \%, \mathrm{n}=205$; Unsure: $54.0 \%, \mathrm{n}=1416$; No response: $8.1 \%, \mathrm{n}=212$ ).

Health Support Pharmacy users were equally likely to express interest as non-users ("Yes" vs all other responses, OR: $1.073, p=0.430$ ), while "collaborating organizations" members were over twice as likely to do so than nonmembers (OR: 2.201, $\mathrm{p}<0.0001$ ).

\section{Factors Associated with Patient Utilization of Pharmacies' Primary-Care and Health-Support Functions: Results of Logistic Regression Analysis}

Table 2 shows the results of logistic regression analysis conducted to identify predictors of utilization of the two official functions of community pharmacies. As noted above, one-stop prescription filling ("Yes" to Q2-2: Figure 2) and interest in attending pharmacist-led informational seminars ("Yes" to Q4-5) were adopted as the proxies for primary-care and health-support functionality (response variables), respectively. Logistic regressions were separately conducted to determine the predictive value of "Yes" responses to questionnaire items (explanatory variables).

The following items were identified as the most significant predictors of primary-care function (Yes vs all other responses): having a primary-care pharmacist (OR: $2.01, \mathrm{p}<0.0001)$, "collaborating organizations" membership (OR:1.54, $\mathrm{p}<0.0001$ ), and positive overall appraisal (OR: $1.50, \mathrm{p}<0.01$ ). Similarly, the following items were identified as the most significant predictors of healthsupport function (Yes vs all other responses): support for pharmacist-led activities out in the community (OR: 2.95, $\mathrm{p}<0.001)$, recognition of the term "Health Support Pharmacy" (OR:2.09, p $<$ 0.001), "collaborating organizations" membership (OR:2.08, $\mathrm{p}<0.001)$, and support for the availability of health consultations at pharmacies (OR:2.01, p < 0.01). Please see Table 2 for a full list of significant predictors of each function, representing important policy targets to improve patients' awareness and knowledge regarding these two functions.

\section{Discussion}

We carried out the present study - a questionnaire survey of 2623 patients who used Min-Iren affiliated community pharmacies - to explore this population's awareness and opinions about their official primary-care and healthsupport functions, as well as identify new challenges facing community pharmacies in Japan. We hypothesized that the attitudes and knowledge of the patients would be influenced by their pharmacy's designation (Health Support Pharmacy vs non-Health Support Pharmacy) as well as membership in Min-Iren "collaborating organizations". However, differences between Health Support Pharmacy users and non-users were rarely statistically significant, with the exception of greater support for 365day pharmacy access among Health Support Pharmacy users compared to non-Health Support Pharmacy users. In contrast, "collaborating organizations" membership was significantly predictive of better utilization of both the primary-care and health-support functions expected of community pharmacies, across a wide range of questions.

Although the Health Support Pharmacy system is confined to Japan, we believe our work is a source of valuable data, given the international support for the idea that community pharmacies should fulfil both primary-care and health-support functions. We report the results of our analysis of patients' needs from Japanese community pharmacies in the hope that our findings could inform and improve community pharmacy-related initiatives in countries across the globe.

\section{Explaining Negligible Differences in Attitudes and Awareness Between Health Support Pharmacy Users and Non-Users}

Just under a third of the participating Min-Iren pharmacies were registered Health Support Pharmacies $(30.4 \%, \mathrm{n}=55)$. However, our data led us to conclude that the majority $(85.1 \%, \mathrm{n}=154)$ fit this designation based on their eligibility for an additional community support system-a 
Table 2 Predictors of Primary-Care and Health-Support Functionality in Community Pharmacies: Results of Logistic Regression Analysis

\begin{tabular}{|c|c|c|c|c|}
\hline \multirow[t]{3}{*}{ X : Explanatory Variables } & \multicolumn{4}{|c|}{ Y : Response Variables } \\
\hline & \multicolumn{2}{|c|}{$\begin{array}{l}\text { 7. One-Stop Filling } \\
\text { (Primary-Care Function) }\end{array}$} & \multicolumn{2}{|c|}{$\begin{array}{l}\text { 16. Seminar Interest } \\
\text { (Health-Support } \\
\text { Function) }\end{array}$} \\
\hline & OR $(95 \% \mathrm{Cl})$ & $p$-value & OR $(95 \% \mathrm{Cl})$ & $p$-value \\
\hline I. HSP user & $1.03(0.86-1.24)$ & & I.05 (0.86-I.29) & \\
\hline 2. Age & $0.95(0.76-1.19)$ & & $0.70(0.54-0.90)$ & $*$ \\
\hline 3. Gender & $1.22(1.01-1.47)$ & $*$ & $0.81(0.66-1.00)$ & \\
\hline 4. Occupational status & $0.87(0.70-1.09)$ & & $1.23(0.96-1.58)$ & \\
\hline 5. CO member & $1.54(1.27-1.86)$ & $* * *$ & $20.8(1.69-2.57)$ & $* * *$ \\
\hline 6. Positive pharmacy appraisal ("Excellent" + "Generally good") & $1.50(1.10-2.03)$ & $* *$ & $1.30(0.91-1.85)$ & \\
\hline 7. One-stop prescription filling & - & & $1.24(1.01-1.52)$ & $*$ \\
\hline 8. Pharmacy usage for reasons besides filling & $1.25(0.96-1.62)$ & & $1.47(1.11-1.94)$ & $* *$ \\
\hline 9. Assigned a primary-care pharmacist & $2.01(1.50-2.68)$ & $* * *$ & I.28 (0.94-I.73) & \\
\hline 10. Support for 24-hour pharmacy access & $1.00(0.78-1.28)$ & & $1.53(1.18-2.00)$ & ** \\
\hline II. Support for 365-day pharmacy access & $1.30(0.98-1.72)$ & & $\mathrm{I} .09(0.8 \mathrm{I}-\mathrm{I} .48)$ & \\
\hline 12. Recognition of term "HSP" & $1.31(1.00-1.73)$ & & $2.09(1.57-2.78)$ & $* * *$ \\
\hline 13. Support for health consultation activities being available at pharmacies & $1.31(0.98-1.76)$ & & $2.01(1.37-2.95)$ & $* *$ \\
\hline 14. Support for simple tests being available at pharmacies & $0.93(0.74-1.16)$ & & $1.49(1.16-1.93)$ & ** \\
\hline 15. Support for pharmacist-led health-promotion activities out in the community & $\mathrm{I} .0 \mathrm{I}(0.78-\mathrm{I} .3 \mathrm{I})$ & & $2.95(2.08-4.18)$ & $* * *$ \\
\hline 16. Interest in attending pharmacy-led seminars on medicine and general health & $1.24(1.01-1.52)$ & $*$ & - & \\
\hline
\end{tabular}

Notes: $* p<0.05, * * p<0.01, * * * p<0.001$. OR $<1.0$ signifies negative correlation.

Abbreviations: OR, odds ratio; $95 \% \mathrm{Cl}, 95 \%$ confidence interval; HSP, Health Support Pharmacy; CO, (Min-Iren) collaborating organization.

premium designed to encourage primary-care functionality $^{28}$ — and stated intentions (or preparations) to register as a Health Support Pharmacy. Given these observations, it stands to reason that most patients were receiving services that fulfilled the obligatory functions of Health Support Pharmacies, regardless of whether the pharmacy in question was officially registered as one. This seems to explain the relative lack of significant differences observed between Health Support Pharmacy users and non-users.

In addition, awareness of the term "Health Support Pharmacy" was extraordinarily low overall, recognized by a mere $12.2 \%$ of the respondents. This result is mirrored by the findings of other recent national surveys which, despite some variation, also observed low public awareness; for example, $8.4 \%$ in an attitude survey conducted by the Japan Pharmaceutical Association (JPA) in September $2018^{29}$ and $19.6 \%$ in a survey conducted by the MHLW in November $2018 .^{25}$ We surmise that this poor public awareness of the Health Support Pharmacy system was a major reason why we observed negligible differences between Health Support Pharmacy users and nonusers.

\section{Explaining High Awareness of Primary-Care and Health-Support Functions Among “Collaborating Organizations" Members}

Min-Iren's mission statement includes the organizational goals of "respecting human rights, advancing medical and long-term care/welfare through joint engagement, and protecting the lives and health of people." 30 The term "joint engagement" (Japanese: kyōdo no itonami) refers to a medical philosophy that regards patients as the focus of healthcare, and healthcare as a collaborative partnership between the healthcare provider and patient. A similar concept is applied to the activities of Min-Iren pharmacies, making cooperating organizations critical allies in this respect.

"Collaborating organizations" members function as "supporters" of Min-Iren medical centers and pharmacies. ${ }^{24}$ These people, which includes a class of citizens who are highly and independently conscious of their health, actively engage in personal- and communityoriented health-promotional activities, in both individual and group settings. For this reason, they probably 
intentionally utilize Min-Iren institutions (eg medical centers, community pharmacies, nursing homes) on a regular basis, and-most relevantly to this discussion-have a greater interest in community pharmacy activities than the average citizen. These qualities seem to explain the wide range of marked differences in opinions and attitudes between "collaborating organizations" members and nonmembers, observed in our survey data.

\section{Interpreting the Findings of Logistic Regression Analysis}

This part of our analysis was an attempt to determine the extent to which patients' responses to each of the items on the survey were predictive of the fulfilment of the primarycare and health-support functions of community pharmacies. The former (Primary-Care Function) was operationalized as patients' utilization of the pharmacy as a "one-stop shop" to fill all prescriptions issued by several providers, while the latter (Health-Support Function) was as utilized for attending pharmacy-led informational seminars on medicine and general health.

Significant associations were observed between Primary-Care Function and male gender, "collaborating organizations" membership, positive pharmacy appraisal, having a primary-care pharmacist, and seminar interest; and between Health-Support Function and "collaborating organizations" membership, one-stop prescription filling, visiting for reasons besides dispensing, and recognition of the term "Health Support Pharmacy," as well as support for 365-day access, availability for health consultations and simple health tests, and pharmacist-led activities out in the community. Notably, "collaborating organizations" membership was a significant predictor of both PrimaryCare Function and Health-Support Function utilization.

Our results suggest that individual pharmacies should lead the way, endeavoring to educate patients to the same level as "collaborating organizations" members, in terms of their awareness of healthpromotional activities and medical care, and raise the health literacy of local residents, in order to improve their appreciation of these two essential community pharmacy functions.

\section{Modern Challenges Facing Community Pharmacies in Japan}

Our survey has yielded a valuable dataset, obtained with the help of 2623 pharmacy users. Older adults (age $\geq 60$ years) comprised the majority of the respondents (71.4\%). In addition, a greater percentage of the respondents were females $(55.9 \%$ vs $43.5 \%$ : Table 1$)$. Our sample had a slightly higher proportion of older adults than the national average (57.5\%) for outpatients in Japan, reported recently by the MHLW. The same survey had a gender ratio (M:F) of $42.5 \%: 57.5 \%{ }^{31}$ The relatively low fraction of working adults in the sample $(29.1 \%)$ can be attributed to the higher proportion of elderly respondents. In addition, the majority of the patients regarded their current pharmacy in a positive light, with 87.0.\% rating their overall service as either "excellent" or "generally good." Below, we discuss some of the challenges currently facing community pharmacies in Japan in view of these and other observations.

\section{Reinforcing the Primary-Care Function of Community Pharmacies}

Over half of the respondents (54.0\%) claimed to not bringing all their prescriptions to the same pharmacy for filling. The major reason for this, cited by $82.5 \%$ of these respondents, was the use of a different pharmacy (or pharmacies) closer to the medical center(s) they regularly visited. However, only $3.2 \%$ of the patients claimed to choose a different pharmacy for each visit. Thus, there seemed to be some degree of consistency regarding which pharmacy (or pharmacies) the patients frequently visit. Nevertheless, our results constitute evidence that about half of the Japanese patients do not get their prescriptions filled at a community pharmacy in their area of residence for reasons of convenience, instead of utilizing ones closer to other providers. This explanation of our results is supported by the fact that - according to one MHLW survey ${ }^{32}$ -approximately $70 \%$ of Japan's community pharmacies are located in close proximity to other medical centers; such offices are commonly known as Monzen ("outfront") pharmacies in Japan.

Relatively few patients acknowledged having utilized their pharmacies for reasons besides dispensing (14.3\%), and still fewer stated that they had been assigned a primary-care pharmacist (12.3\%). There was an almost 2.5 -fold disparity in the utilization of pharmacies for purposes besides dispensing between patients with $(30.1 \%$, $\mathrm{n}=98 / 326)$ and without a primary-care pharmacist $(11.7 \%, \quad \mathrm{n}=222 / 1901)$ (cross-tabulation; data not shown). This suggested that the assignment of a primarycare pharmacist was a key factor driving the utilization of 
community pharmacies for purposes apart from filling prescriptions. However, other observed trends suggested that the significance of the primary-care pharmacist role has not fully penetrated the public consciousness, as sizeable percentages of respondents reported either not wanting one $(22.2 \%)$ or being unsure on the matter (41.5\%). In a qualitative analysis done by Norose and colleagues on patients' expectations of primary-care pharmacists, the importance of high behavioral and ethical standards required of medical providers was demonstrated as the prerequisites to being appreciated as such. ${ }^{33}$ On another note, Moro and colleagues identified issues that now face pharmacists due to the specific requirements of the primary-care pharmacist framework, including the increased burden created by the requirement of 24-hour availability. ${ }^{34}$ Further verification of the significance and utility of the designation "primary-care pharmacist" is needed in the future.

Our participants did not seem to have particularly high expectations of uninterrupted service, with only $26.6 \%$ and $17.1 \%$ claiming they agreed that pharmacies should be open 365 days per year and 24 hours per day, respectively. In addition, "collaborating organizations" members rejected these ideas at very high rates. Osanai et al reported that only $22.0 \%$ of the community residents had a desire to contact their pharmacies outside of normal operating hours (eg holidays, night-time) to consult about medications. ${ }^{35}$ These trends suggest that rather than simply keeping the pharmacy offices open, ensuring that the pharmacists are available anytime for phone consultations, including holidays and at night, would better satisfy the public's needs.

Our analysis leads us to conclude that optimizing the location(s) of community pharmacies and ensuring to assign a designated primary-care pharmacist for each patient are two critical tasks that may help to reinforce the primary-care functionality of the community pharmacies. The words "pharmacist" and "pharmacy" are written side by side in the MHLW's Pharmacy Vision for Patients, as "primary-care pharmacists/pharmacies" (Figure 1). ${ }^{21}$ Even Monzen pharmacies can be adapted to serve as primary-care pharmacies for patients who live in their vicinity. To achieve these goals, policies should encourage pharmacists to further improve their professional skills and strengthen the centralized management of prescriptions.

\section{Reinforcing the Health-Support Function of Community Pharmacies}

Respondents had a positive attitude regarding activities related to the health-support function of community pharmacies, with the majority of them expressing support for access to health consultations (78.7\%) and blood-glucose monitoring and other simple tests at their pharmacies $(65.8 \%)$, as well as pharmacist-led health-promotional activities in the community $(74.4 \%)$. Others expressed interest in attending pharmacist-led information seminars on medicine and general health (30.1\%). While the pharmacy status (Health Support Pharmacy vs non-Health Support Pharmacy) had no effect on the users' responses, "collaborating organizations" members were significantly more likely to support all these activities (with the exception of simple testing) than non-members. Iwata et al reported that only $40 \%$ of the participants in a special event organized to measure the levels of blood lipid and other biomarkers knew that such simple tests could be done at community pharmacies. ${ }^{36}$ Perhaps this low baseline awareness in the population explains why "collaborating organizations" membership had no effect on the awareness of this community pharmacy service.

Omori emphasized the importance of pharmacists in community pharmacies not limiting their responsibilities to home-based care and argued for their greater engagement in communities through partnerships with school pharmacists and government. ${ }^{37}$ The fact that nearly threequarters of our respondents supported the idea of pharmacists reaching out to their communities to run health-promotional activities (74.4\%) reflects the existence of high awareness of such activities amongst them, perhaps expressing their expectations of pharmacy services in the future.

The overall low interest of the respondents to participate in seminars held at their pharmacy (30.1\%) may not be merely due to the lack of "public awareness" but could be attributed to the shortage of time to attend these seminars. Min-Iren "collaborating organizations" members had a higher and more-independent motivation in improving their health, a result of their regular participation in "collaborating organizations"-sponsored events. Similarly, "collaborating organizations" members (vs non-members) were more than twice as likely to express interest in seminars (in terms of odds ratio) when compared to Health Support Pharmacy users (vs non-users). Therefore, we believe that community pharmacies can raise public awareness of health 
promotion, even among those unaffiliated with "collaborating organizations" memberships, by proactively strengthening their health-support function-related approaches for pharmacy users and community residents.

\section{Conclusion}

This study is the first-ever large-scale opinion-based survey of Japanese users of Min-Iren member pharmacies to address the primary-care and health-support functions of these pharmacies. Our findings shed new light on the disappointingly low awareness regarding Health Support Pharmacies among patients, even three years after the system's inauguration. Patients who were more proactive and conscious of health promotion, represented by members of Min-Iren "collaborating organizations", such as medical co-ops and Friends of Health, were found to have a better understanding of the variety of services provided at community pharmacies, and positively rated the services of their pharmacies. However, further research on these topics is warranted. Nonetheless, community pharmacies - and especially Health Support Pharmacies - can take steps to further promote patients' health, which could generate a greater public appreciation of the services provided by them with respect to their official primary-care and healthsupport functions. In addition, the pharmacists working at community pharmacies should be more proactive in reaching out to their communities and act as the driving force behind disseminating and improving the knowledge of local residents about health promotion. In the future, we would like to study whether there is a difference in the utilization of regional pharmacies due to illness.

\section{Acknowledgments}

The authors wish to extend their deepest gratitude to the Japan Federation of Democratic Medical Institutions, as well as all the pharmacists and their administrative staff for their assistance.

\section{Disclosure}

The authors report no conflicts of interest in this work.

\section{References}

1. Tin FS, Wright B, Hattingh L, et al. A cross-sectional survey of enhanced and extended professional services in community pharmacies: A pharmacy perspective. Res Soc Adm Pharm. 2020;16 (4):511-521. doi:10.1016/j.sapharm.2019.07.001
2. Petrelli F. The pharmacist's role in health information, vaccination and health promotion. Ann Ig. 2019;31:309-315.

3. Krska J, Lovelady C, Connolly D, et al. Community pharmacy contribution to weight management identifying opportunities. Int J Pharm Pract. 2010;18(1):7-12. doi:10.1211/ijpp.18.01.0003

4. Brown TJ, Todd A, O'Malley C, et al. Community pharmacy-delivered interventions for public health priorities: a systematic review of interventions for alcohol reduction, smoking cessation and weight management, including meta-analysis for smoking cessation. BMJ Open. 2016;6(2):1-18. doi:10.1136/bmjopen2015-009828

5. Brown D, Portlock J, Rutter P, et al. From community pharmacy to health living pharmacy: positive early experiences from Portsmouth, England. Res Soc Adm Pharm. 2014;10(1):72-87. doi:10.1016/j. sapharm.2013.04.014

6. Anderson C, Blenkinsopp A, Armstrong M, et al. Feedback from community pharmacy users on the contribution of community pharmacy to improving the public's health: a systematic review of the peer reviewed and non-peer reviewed literature 1990-2002. Health Exp. 2004;7(3):191-202. doi:10.1111/j.1369-7625.2004.00274.x

7. Amesty S, Blaney S, Crawford ND, et al. Pharmacy staff characteristics associated with support for pharmacy-based HIV-testing in pharmacies participating in the New York State Expanded Access Syringe Exchange Program. $J$ Am Pharm Assoc. 2012;52 (4):472-479. doi:10.1331/JAPhA.2012.10194

8. Ohmisu M, et al. Current status of bioanalytical labs in the saga pharmaceutical association's self-measurement of blood glucose in community pharmacies project. Jpn Soc Pharm. 2019;38:27-31.

9. Hall B, Kelly F, Wheeler AJ, et al. Consumer perceptions of community pharmacy-based promotion of mental health and well-being. Health Promot J Austr. 2019. doi:10.1002/hpja.312

10. Suzuki R, Suzuki T, Kikuchi C, et al. Improvements in lifestyle from a lifestyle consecutive self-review at a pharmacy. Yakugaku Zasshi. 2019;139(7):1047-1054. doi:10.1248/yakushi.18-00187

11. Osanai Y, Sakurai H, et al. Examination of usefulness of various health consultations in a community pharmacy among the residents. Jpn J Pharm Health Care. 2019;45(6):312-321. doi:10.5649/jjphcs. 45.312

12. Morecroft KJ. CW. Views of the general public on the role of pharmacy in public health. $J$ Pharm Health Services Res. 2010;1:33-38.

13. Hirota N, Inagaki M, Matsumura N, et al. An outcome evaluation of health support pharmacy efforts to improve health literacy. Jpn J Pharm Health Care. 2018;44(5):244-250. doi:10.5649/jjphcs.44. 244

14. Suzuki S, Uchida M, Suga Y, et al. A nationwide survey of community pharmacist contributions polypharmacy in opioid-using and non-using cancer patients in japan. Biol Pharma Bull. 2019;42 (7):1164-1171. doi:10.1248/bpb.b19-00043

15. Donald M, King-Shier K, Tsuyuki RT, et al. Patient, family physician and community pharmacist perspectives on expanded pharmacy scope of practice: a qualitative study. CMAJ Open. 2017;5 (1):205-212. doi:10.9778/cmajo.20160135

16. Anderson S. Community pharmacy and public health in Great Britain 1936 to 2006: how a phoenix rose from the ashes. J Epidemiol Community Health. 2007;61(10):844-848. doi:10.1136/jech.2006.055442

17. Motulsky A, et al. Patient-initiated consultations in community pharmacies. Res Social Adm Pharm. 2020. doi:10.1016/j.sapharm.20 20.03.001

18. Saito M. Current status of community pharmacies: expectations as a health information hub, the enforcement of reviewed pharmaceutical and medical device act, and a new role as stakeholders. Yakugaku Zasshi. 2016;136:245-249. doi:10.1248/yakushi.15-00268-1

19. Cabinet Office. First Year of Reiwa White Paper on Aging Society. 2019; Available from: https://www8.cao.go.jp/kourei/whitepaper/ w-2019/zenbun/pdf/1s1s_01.pdf/. Accessed 25 April, 2020. 
20. Ministry of Health, Labour and Welfare. Local inclusion system. 2014; Available from: https://www.mhlw.go.jp/stf/seisakunitsuite/ bunya/hukushi_kaigo/kaigo_koureisha/chiiki-houkatsu/. Accessed 25 April 2020.

21. Ministry of Health, Labour and Welfare. Pharmacy vision for patients. 2015; Available from: https://www.mhlw.go.jp/file/04Houdouhappyou-11121000-Iyakushokuhinkyoku-Soumuka/vision_1. pdf/. Accessed 25, April 2020.

22. Sato N, et al. Exploring the factors influencing the quality of "Health Support Pharmacy" services in Japan: perspectives of community pharmacy. Res Soc Adm Pharm. 2015. doi:10.1016/j.sapharm.2020.02.012

23. Hirota N, Okamura N. The Japanese community pharmacists' perceptions of the health support pharmacy system. Pharmacology Pharmacy. 2020;11(04):55-70. doi:10.4236/pp.2020.114006

24. Japanese Federation of Democratic Medical Institutions (Min-Iren). Available from: https://www.min-iren.gr.jp/. Accessed 25 April, 2020.

25. Ministry of Health, Labour and Welfare. Survey report on family pharmacist/pharmacy. Available from: https://www.mhlw.go.jp/con tent/000507664.pdf/. Accessed 25 April 2020.

26. Nutbeam D. Health literacy as a public goal: a challenge for contemporary health education and communication strategies into the 21 st century. Helth Promot Int. 2000;15:259-267. doi:10.1093/heapro/15.3.259

27. Kanda Y. Investigation of the freely available easy-to-use software 'EZR' for medical statistics. Bone Marrow. 2013;48:542-548.

28. Ministry of Health, Labour and Welfare. Heisei 30 nendo chouzai housyu kaitei no gaiyou. 2018; Available from: https://www.mhlw.go. jp/file/06-Seisakujouhou-12400000-Hokenkyoku/0000197985.pdf/. Accessed 25, April 2020.

29. Japan Pharmacists Association. Attitude survey on health support and pharmacists. Available from: https://www.nichiyaku.or.jp/assets/ uploads/pr-activity/PressRelease_20181129.pdf/. Accessed 25 April 2020.
30. Japanese Federation of Democratic Medical Institutions (Min-Iren). Mission Statement. Available from: https://www.min-iren.gr.jp/wpcontent/uploads/2013/01/koryo100517_02.pdf/. Accessed 25 April 2020 .

31. Ministry of Health, Labour and Welfare. Outline of patient survey in 2017. Available from: https://www.mhlw.go.jp/toukei/saikin/hw/ kanja/17/dl/01.pdf/. Accessed 25 April 2020.

32. Ministry of Health, Labour and Welfare. Special survey results regarding verification of results of medical fee revision in 2018. Available from: https://www.mhlw.go.jp/content/12404000/ 000566779.pdf/. Accessed 25 April 2020.

33. Norose $\mathrm{T}$, et al. What does a patient expect of a family pharmacist ?: qualitative analysis based on a focus group. Jpn Soc Pharm. 2018;37:117-126.

34. Moro $\mathrm{Y}$ et al. Elucidation od the current situation of family pharmacist system and the problems seen from pharmacists. The 140th Annual Meeting of the Pharmaceutical Society of Japan (Kyoto). 2020

35. Osanai Y, Kimura R, Takasugi K, et al. Difference in importance about consultation contents of medicine in out-of-hours and the time of the opening of a pharmacy and the evaluation. Jpn J Pharm Health Care. 2018;44(6):288-298. doi:10.5649/jjphcs.44.288

36. Iwata $\mathrm{H}$, et al. A study on the usefulness of a simple lipid measurement for the early detection of dyslipidemia and recognition of dyslipidemia among local residents. Jpn Soc Pharm. 2016;35:80-86.

37. Omori M. Think about a pharmacist/pharmacy in the insurance pharmacy. YAKUHAKU ZASSHI. 2019;139:525-527. doi:10.1248/ yakushi.18-00172-3
Integrated Pharmacy Research and Practice

\section{Publish your work in this journal}

Integrated Pharmacy Research and Practice is an international, peerreviewed, open access, online journal, publishing original research, reports, reviews and commentaries on all areas of academic and professional pharmacy practice. This journal aims to represent the academic output of pharmacists and pharmacy practice with particular focus on integrated care. All papers are carefully peer reviewed

\section{Dovepress}

to ensure the highest standards as well as ensuring that we are informing and stimulating pharmaceutical professionals. The manuscript management system is completely online and includes a very quick and fair peer-review system, which is all easy to use. Visit http://www.dovepress.com/testimonials.php to read real quotes from published authors. 